\title{
Long-term control of carbapenemase-producing Enterobacteriaceae at the scale of a large French multihospital institution: a nine-year experience, France, 2004 to 2012
}

S Fournier (sandra.fournier@sap.aphp.fr) ${ }^{1}$, C Monteil $^{1}$, M Lepainteur $^{1}$, C Richard $^{2}$, C Brun-Buisson 3 , V Jarlier ${ }^{4}$, AP-HP Outbreaks Control Group 5

1. Infection Control Team, Direction de la Politique Médicale, Assistance Publique-Hôpitaux de Paris, Paris, France

2. Hôpital Bicêtre, Assistance Publique-Hôpitaux de Paris, Le Kremlin-Bicêtre, France

3. UPEC Univ Paris 12, Hôpital Henri Mondor, Assistance Publique-Hôpitaux de Paris, Créteil, France

4. Infection Control Team, Direction de la Politique Médicale, UPMC Univ Paris 06, EA 1541, laboratoire de Bactériologie, Hôpital

Pitié-Salpêtrière, Assistance Publique-Hôpitaux de Paris, Paris, France

5. The members of the AP-HP Outbreaks Control Group are listed at the end of the article

Citation style for this article:

Fournier S, Monteil C, Lepainteur M, Richard C, Brun-Buisson C, Jarlier V, AP-HP Outbreaks Control Group. Long-term control of carbapenemase-producing

Enterobacteriaceae at the scale of a large French multihospital institution: a nine-year experience, France, 2004 to 2012. Euro Surveill. 2014;19(19):pii=20802.

Available online: http://www.eurosurveillance.org/ViewArticle.aspx?Articleld =20802

Article submitted on 22 April 2013 / published on 15 May 2014

In 2009, following the occurrence of several outbreaks of carbapenemase-producing Enterobacteriaceae (CPE), a programme for controlling the spread of CPE was implemented in the 38 hospitals of the Assistance Publique-Hôpitaux de Paris, a 21,000-bed institution. This programme included recommendations to isolate, and screen for CPE, patients previously hospitalised abroad, and bundled measures to control cross transmission (barrier precautions, dedicated staff and screening of contact patients). From 2004 to 2012, 140 CPE index cases were identified, 17 leading to outbreaks. After application of the programme, in spite of an increase in the number of CPE index cases epidemiologically linked with a recent stay or hospitalisation abroad, the proportion of cases followed by outbreaks, which was $40 \%(4 / 10)$ before 2009 , decreased to $10 \%(13 / 130)(p=0.02)$, and the proportion of secondary cases among all CPE cases decreased from $69 \%(22 / 32)$ to $23 \%(38 / 168)$, (p<0.001). The number of secondary cases varied significantly depending on the speed and strength of the measures implemented around the CPE index case: quick (within two days of patient admission at the hospital) setting of nursing staff dedicated to the patient, quick setting of simple barrier precautions, or delayed measures of control $(p=0.001)$. A sustained and coordinated strategy can lead to control CPE at the level of a large regional multi-hospital institution in a country where CPE are at an emerging stage.

\section{Introduction}

Carbapenemase-producing Enterobacteriaceae (CPE) are nowadays a major public health concern worldwide, since carbapenems represent the last line betalactam antibiotics for treating patients infected by multidrug resistant Enterobacteriaceae [1]. In 2011, the prevalence in European countries, as reported in percentage of carbapenem resistance among Klebsiella pneumoniae, varied significantly from high (e.g. $>15 \%$ in Greece, Cyprus, or Italy) to extremely low (e.g. ${ }_{1} \%$ in Nordic countries, United Kingdom, or Spain) [2]. High prevalence in K. pneumoniae and Escherichia coli has been recently reported in India and Pakistan and subsequently, a link between this high prevalence and the occurrence of CPE in hospitals in the United Kingdom has been demonstrated [3].

In France, resistance to carbapenems due to carbapenemases is so far uncommon among Enterobacteriaceae as shown by the European Antimicrobial Resistance Surveillance Network (EARS-net) [4]. Nevertheless, several outbreaks, the majority of which were limited in size, occurred in French hospitals in the past few years, most often involving patients with a history of hospitalisation abroad [5]. The first outbreak of CPE in France occurred in 2004, in one of the hospitals of Assistance Publique-Hôpitaux de Paris (AP-HP), the largest public health institution in France, and happened following the transfer of a patient from a Greek hospital [6]. This outbreak triggered the implementation of a long-term programme for surveillance and control of CPE in this institution. We describe here the results of this programme in AP-HP hospitals during a nine-year period, from 2004 to 2012.

\section{Methods}

\section{Setting}

AP-HP is a public health institution administering 38 teaching hospitals (22 acute care (AC) and 16 
rehabilitation/long-term care (RLTC) hospitals, spread over Paris, suburbs and surrounding counties), with a total of 21,000 beds ( $10 \%$ of all public hospital beds in France) and serving 12 million inhabitants. AP-HP admits approximately one million inpatients per year, employs 22,000 physicians, 20,000 nurses and 30,000 assistant nurses. Local administrators and medical committees manage AP-HP hospitals, but decisions on large investments and medical developments are made by the central administration. In each hospital, a local infection control team (LICT) is in charge of prevention and surveillance of healthcare-associated infections, but decisions of foremost importance for the whole institution, e.g. multidrug resistance control programme, are coordinated by a multidisciplinary central infection control team (CICT), including one infectious disease physician, one bacteriologist, one epidemiologist and one nurse [7].

\section{Case definitions}

A case was defined as any patient infected or colonised with CPE. A contact patient was defined as any patient whose stay overlapped with the stay of a CPE case for at least one day in the same unit. An outbreak was defined as at least two CPE cases (i.e. one index case and at least one secondary case among the contact patients) occurring in a given hospital, with a clear epidemiological link (stay during the same period of time in the same unit) and involving indistinguishable CPE strain based on species, antibiotic susceptibility and carbapenemase enzyme. An event was defined as one index case, followed or not by secondary case(s).

\section{Carbapenemase-producing Enterobacteriaceae control programme}

In 2004, following the first CPE outbreak, every LICTs was asked to promptly report every new CPE case to the AP-HP CICT. For each CPE event, the following data were collected: the unit where the event occurred, the number of cases, the clinical status of the cases (infection or colonisation), the bacterial species and type of carbapenemase, the presence of an epidemiological link between the index case and a foreign country (any country outside France), and the nature of this link (e.g. direct transfer from a foreign hospital, previous hospitalisation abroad or previous stay abroad without hospitalisation, within the preceding year).

Moreover, for each CPE event, AP-HP CICT asked LICT to apply a bundle of measures to prevent cross transmission. These measures were based on the experience acquired to control the first CPE outbreak [6]:

i the day of CPE identification, barrier precautions around the CPE case had to be implemented; nursing staff, as far as possible, had to be dedicated to the case, the hospital administrator had to be alerted; transfers of the case and contact patients to other units of the hospital or to other hospitals had to be stopped; contact patients had to be screened for CPE by culturing rectal swabs;

ii the following days and until the discharge of index CPE case, CPE screening had to be extended to contact patients already transferred from the involved unit at the time of index case identification; screening of contact patients had to be pursued once weekly; hand hygiene had to be reinforced with the use of alcohol-based hand-rub solutions; the cleaning of the CPE patient's environments had to be reinforced using detergent-disinfectant product; antibiotics that could be used in case of serious infection due to the strain of the index case had to be identified;

iii if no secondary case was identified, the transfer of contact patients, if needed, was allowed providing that three consecutive rectal swabs, obtained on a weekly basis, were negative; screening of contact patients hospitalised in the involved unit had to be pursued until the discharge of index CPE case;

iv if a secondary case was identified, patients had to be cohorted in three distinct areas with dedicated nursing staff ('CPE patients' section, 'contact patients' section and 'CPE-free patients' section for newly admitted patients with no previous contact with (PE cases); and screening once weekly had to be maintained for all contact patients until the outbreak was considered under control, i.e. after all CPE cases had been discharged and after at least three consecutive negative rectal swabs in contact patients since their last contact with a case; screening of contact patients receiving antibiotics had to be resumed; transfer of contact patients after three negative rectal swabs was allowed provided they continued to be isolated and screened for CPE; antibiotics use was restricted; the list of cases and contact patients discharged from hospitals had to be maintained and an information system allowing to identify them in case of re-admission had to be implemented.

In 2009, after the analysis of the CPE events, occurring during the first years of surveillance had shown not only frequent delays in identifying the index case and subsequent implementation of measures, but also that most index cases (8/10, including $3 / 4$ outbreaks) had been transferred from a foreign hospital, an institutional CPE programme was designed and coordinated by the AP-HP CICT. This programme included the above measures, which were detailed in an official document, and the recommendation to pre-emptively isolate (barrier precautions) and screen for CPE, every patient who had been hospitalised abroad within the preceding year. The programme emphasised the need of a rapid and stringent application of the measures, as well as the commitment of the hospital management. This programme was disseminated to all stakeholders, i.e. LICTs, medical managers and administrators of every hospital in the institution. 
To stimulate the efforts made by the LICTs and administrators, the CICT (i) visited all the hospitals where an outbreak occurred, to help the local teams apply the CPE programme, (ii) prospectively recorded new cases, new outbreaks, and difficulties in implementing the programme, and (iii) regularly shared the results of this surveillance with hospitals and the central administration.

\section{Microbiological methods}

To screen patients for CPE carriage, rectal swabs were cultured on chromogenic agar targeting cephalosporin-resistant Enterobacteriaceae. Indeed, CPE strains are frequently resistant to cephalosporins due to the production of the carbapenemase itself or to the production of an additional extended spectrum beta-lactamase (ESBL). Cephalosporin-containing chromogenic agars are widely used in France for the surveillance of multiresistant bacteria targeting ESBL Enterobacteriaceae [8]. Screening for carbapenemaseproducing strains without associated ESBL was performed using an ertapenem-containing agar [9].

Isolates from clinical specimens and rectal swabs were tested for susceptibility to antibiotics according to French guidelines [8]. In carbapenem resistant strains, carbapenemase production was detected using a set of phenotypic (e.g. synergy tests between carbapenems and carbapenemase inhibitors) and genotypic (carbapenemase gene amplification and sequencing) methods [9].

\section{Statistical analysis}

To evaluate the impact of the CPE programme, we compared the proportion of events resulting in an outbreak and the number of secondary cases occurring during these outbreaks in the period before (2004-2009) and after its implementation in 2009 (2010-2012).

Depending on whether the index case was identified/ suspected upon admission or not, measures to prevent secondary cases (setting of nursing staff dedicated to the patient, or setting of simple barriers precautions) were quickly implemented (i.e. within two days of admission of the patient), or delayed for several days. We compared the proportion of events resulting in an outbreak and the number of secondary cases occurring during these outbreaks in these different situations.

The data were analysed with Stata. Quantitative variables were described using numbers and percentage or median and interquartile range (IQR). A chi-squared test and a Fischer exact test were used to compare categorical variables. A p value $<0.05$ was considered statistically significant.

\section{Results}

Carbapenemase-producing Enterobacteriaceae events and outbreaks

From January 2004 to December 2012, 140 CPE events occurred in AP-HP hospitals. The number of annual events, which was limited to one or two events per year before 2009 increased dramatically thereafter reaching 73 events in 2012, i.e. an incidence of 0.007 CPE events per 100 admissions in 2012. Among the 140 events, 118 (84\%) involved patients with a history of hospitalisation or stay abroad within the past year. Seventy-four were directly transferred from foreign hospitals, 25 had been hospitalised in foreign hospitals during the last 12 months and 19 reported a recent stay (within one year) in a foreign country. Link with involved species and countries of travel are described elsewhere [10].

Seventeen of the 140 events (12\%) led to outbreaks. Overall 200 cases were identified, among them, 123 $(62 \%)$ were single cases (i.e. index cases not followed by secondary cases) and 77 (39\%) were clustered in the 17 outbreaks ( 17 index cases and 60 secondary cases). The median number of secondary cases per outbreak was 1 (IQR: $1-4)$. The median duration of outbreaks was 22 days (IQR: 15-66). Three of these outbreaks have been already described in details $[6,11,12]$. One of them involved two AP-HP hospitals revealing interhospital spread of a strain of $K$. pneumoniae producing K. pneumoniae carbapenemase (KPC) [11].

The 140 events occurred in 25 distinct AP-HP hospitals (20 AC, and 5 RLTC hospitals) involving medical $(n=63$, $45 \%)$, intensive care $(n=46,33 \%)$ or surgical $(n=31$, $22 \%)$ units. Outbreaks occurred mainly in AC hospitals $(n=16)$, involving intensive care $(n=6)$, surgical $(n=6)$ or medical $(n=4)$ units; one outbreak occurred in a RLTC hospital.

\section{Microbiology}

The main species involved in events were $K$. pneumoniae $(\mathrm{n}=96,69 \%)$, E. coli $(\mathrm{n}=36,26 \%)$, Enterobacter cloacae $(\mathrm{n}=10,7 \%)$, Citrobacter freundii $(\mathrm{n}=4,3 \%)$, and Enterobacter spp. ( $\mathrm{n}=4,3 \%)$. In 10 events, two distinct species, generally $K$. pneumoniae and $E$. coli, were involved. K. pneumoniae and $E$. coli were involved in 15 and two outbreaks respectively.

The carbapenemases identified were oxacillinase (OXA)-48 $(n=82,59 \%)$, KPC $(n=31,22 \%)$, New Delhi metallo-beta-lactamase (NDM)-1 $(n=17,12 \%)$, and Verona integron-encoded metallo-beta-lactamase (VIM) $(n=10,7 \%) . K P C$, OXA-48 and VIM were involved in eight, eight and one outbreaks, respectively.

\section{Characteristics of carbapenemase-producing}

Enterobacteriaceae cases

Among the 200 case patients, 66 (33\%) developed an infection: $27(41 \%)$ were urinary tract infections, 22 (33\%) bacteraemia, seven (11\%) osteoarticular 
Number of carbapenemase-producing Enterobacteriaceae (CPE) events $(n=140)$ and proportion of outbreaks among these events at Assistance Publique-Hôpitaux de Paris, France, 2004-2012

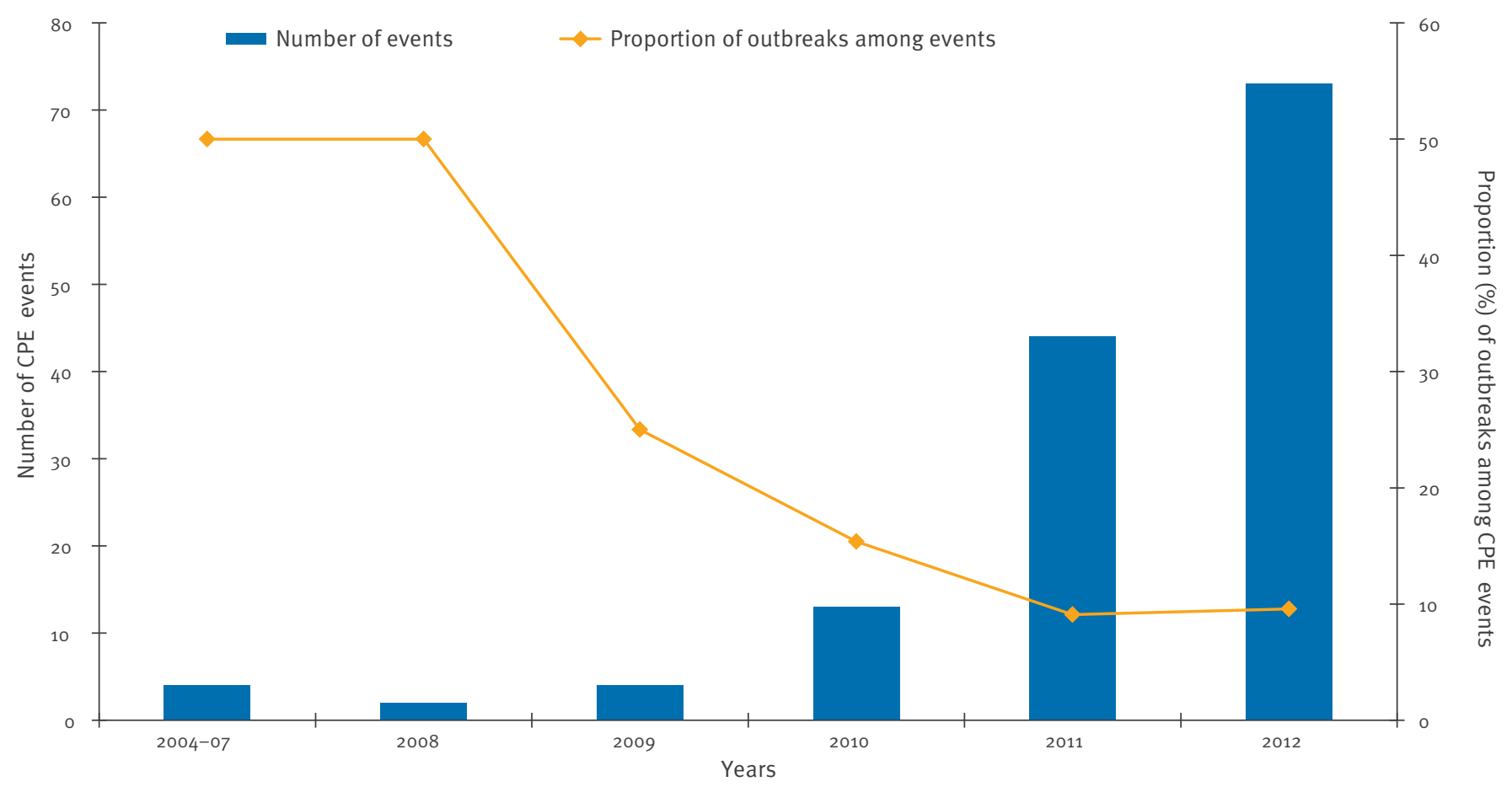

A CPE event was defined as one index case (respectively defined as infected or colonised with CPE), followed or not by secondary case(s).

infections, six (9\%) cutaneous infections, and four (6\%) bronchopulmonary infections. Incidence of CPE infection was 0.004 per 1,000 hospital days in 2012. The crude case-fatality rate was $22 \%$ (43/200); 14 patients died with severe infection (bacteraemia or bronchopulmonary infections). The median length of hospitalisation, available for 176 patients, was 25 days (IQR: 12-53).

\section{Impact of carbapenemase-producing}

\section{Enterobacteriaceae control programme}

The proportion of events leading to outbreaks decreased progressively from 50\% (3/6) in the period between 2004 and 2008 , i.e. before the full implementation of the institutional CPE programme, to $10 \%$ (4/44) in 2011, a level that was maintained in 2012. The Figure illustrates the evolution of number of events and the proportion of outbreaks among the events.

Moreover, the proportion of secondary cases among all the cases decreased significantly from $69 \%(22 / 32)$ in the period from 2004 to 2009 to $23 \%(38 / 168)$ in the period from 2010 to 2012, $p<0.001$ respectively (Table 1). Also, while the number of index cases increased more than four times in the period after implementation of the CPE control programme, the number of additional secondary cases was less than one-fold higher.

The type and timeliness of measures implemented depended on whether the index case had been identified upon admission or not. If the index case was known to be a CPE carrier, dedicated nursing staff or at least barrier precautions, depending on availability of nursing staff, was implemented immediately after admission. If the index case was known to be at risk to be a CPE carrier, i.e. if the patient had been hospitalised abroad, simple barrier precautions were implemented, waiting the results of screening. If the index case was not known to be a CPE carrier and was not identified to be at risk at admission, implementation of control measures was delayed until the identification of CPE carriage, for example on a clinical specimen, several days or sometimes several weeks (range: 1-8 weeks), after admission. The important finding was that no outbreak occurred when dedicated nursing staff was implemented within two days following the admission of the index case, six outbreaks occurred despite barrier precautions implemented within these two days, whereas 11 outbreaks occurred when measures were delayed because the index case was identified several days after admission. Moreover, the proportion of secondary cases among all cases within a given event varied significantly from o (0\%), to 19 (26\%) and 41 (38\%) respectively, depending on the speed and strength of the measures implemented (Table 2).

\section{Discussion}

This prospective multicentre study, carried out in the largest French public multi-hospital institution, representing $10 \%$ of the public hospital beds in France, 
Number of carbapenemase-producing Enterobacteriaceae (CPE) outbreaks among CPE events and number of secondary cases among all CPE cases, before and after implementation of a CPE control programme at Assistance Publique-Hôpitaux de Paris, France, 2004-2012

\begin{tabular}{|l|c|c|}
\hline & $2004-2009$ & $2010-2012$ \\
\hline Number of events & 10 & 130 \\
\hline Number of outbreaks (proportion of outbreaks among events) & $4(40 \%)$ & $13(10 \%)$ \\
\hline Number of cases & 32 & 168 \\
\hline $\begin{array}{l}\text { Number of secondary cases (proportion of secondary cases among } \\
\text { total cases) }\end{array}$ & $22(69 \%)$ & $38(23 \%)$ \\
\hline
\end{tabular}

Over the whole period from 2004 to 2012 there were a total of 17 outbreaks among 140 CPE events and 60 secondary cases among 200 CPE cases.

aimed to assess the impact of an institutional control programme implemented for limiting CPE spread. The main result of the programme was the decrease over time in CPE outbreaks and in the proportion of secondary cases among all cases, in spite of the increase in CPE index cases. The increase in CPE index cases appears to be epidemiologically linked with a history of hospitalisation or stay abroad, a phenomenon also documented by French Health authorities [13]. To our knowledge, the present study reports the largest experience of a CPE control programme in a country where CPE are still at an emerging stage (sporadic hospital outbreaks, [14]). Indeed, data from the 2011 European survey antimicrobial resistance interactive database (EARS-net) show that the proportion of carbapenemresistant isolates of $K$. pneumoniae and $E$. coli was $<0.5 \%$ and almost $0 \%$, respectively in France [4]. A specific early warning system organised by the French Health authorities at the national level to systematically collect information on CPE cases, reported 113 cases in 2011 for the whole country [13]. Bundle measures similar to those described in the present study have been associated with the limitation of CPE spread in Israel where CPE are endemic [15-17].
This study also highlights the importance of the type of measures and the way these are implemented to limit the number of secondary cases, in particular the speed of implementation of dedicated nursing staff. The type and timeliness of measures implemented after admission of the index case influenced significantly the number of secondary cases (Table 2 ): quick ( $\leq 2$ days after admission) setting of nursing staff dedicated to the index case, quick implementation of simple barrier precautions or delayed ( $>2$ days after admission) measures of control. Interestingly, as already reported by others [16], rapidly isolating index patients with barrier precautions was not always sufficient to avoid secondary cases and these occurred in six of 55 events (Table 2). Dedicated nursing staff is probably one of the most relevant measure to avoid cross transmission [15,17-19]. In the context of an epidemic, cohorting patients with dedicated nursing staff in three different groups (cases, contacts and newly admitted patients) was shown to be effective in controlling the outbreak $[6,11,17]$. The present study shows that dedicating staff to an index case carrying CPE also prevents the occurrence of outbreaks. However, limitation in nursing staff can present an obstacle to assigning several healthcare workers to a single case. Implementation of cohorting requires a strong and sustained involvement

\section{TABLE 2}

Occurrence of outbreak and number of secondary cases according to measures implemented around a carbapenemaseproducing Enterobacteriaceae (CPE) index case at Assistance Publique-Hôpitaux de Paris, France, 2004-2012

\begin{tabular}{|l|c|c|c|}
\hline \multirow{2}{*}{$\begin{array}{l}\text { Event }{ }^{\mathrm{a}} \text { and related cases } \\
\text { Number of events }\end{array}$} & $\begin{array}{c}\text { Measures implemented within two } \\
\text { days following admission of the } \\
\text { index case }\end{array}$ & $\begin{array}{c}\text { Dedicated } \\
\text { nursing staff }\end{array}$ & $\begin{array}{c}\text { Delayed } \\
\text { precautions } \\
\text { measures of } \\
\text { control }\end{array}$
\end{tabular}

\footnotetext{
a An event was defined as one index case, followed or not by secondary case(s).

${ }^{b}$ Control measures were implemented but occurred later than two days after admission of the index case, because the patient was not identified as infected/colonised with CPE within the first days of admission.
} 
of chief nurses and heads of departments, as well as administrators. Such measures already allowed to control the spread of vancomycin resistant enterococci in our institution [20].

Identification of patients transferred from or previously hospitalised abroad in the prior year was most likely crucial, as this allowed to rapidly screen these patients at risk to be colonised by a CPE strain and to implement pre-emptive barrier precautions to avoid transmission to other patients [21]. This recommendation has been subsequently extended at the national level by French Health authorities in August 2010 [22], a measure that could have contributed to improve adherence to organising early screening of such patients in our institution. The increase in CPE index cases in our institution, mainly in 2011 and 2012, reflects the worldwide spread of CPE, since $84 \%$ of cases in our study had a history of hospitalisation or stay abroad, within the past year. In certain regions of the world, the spread of carbapenemases (NDM-1 and OXA-48) occurs primarily in the community via the faecal-oral route, either by food or water-borne transmission [3,23]. In industrialised countries with safe water systems and good sanitation, CPE are up to now acquired almost exclusively in the healthcare setting [23]. In a country with low prevalence of CPE such as France, it appears essential to identify CPE carriers upon their admission in hospitals in order to further implement adequate control measures [22]. Indeed, in the present study, most outbreaks and secondary cases occurred following delayed identification of index case patients.

Screening contact patients to rapidly identify crosstransmission was likely also important to limit the spread of CPE in our study. Indeed, active screening of contact patients has been shown to be very effective to identify CPE carriers $[24,25]$. Stopping the transfer of CPE index or secondary cases and the transfer of contact patients within and between hospitals most likely contributed to decrease the risk of CPE spreading in our institution. Indeed, extensive transfer of KPC positive patients has been reported to account for a regional spread affecting at least 26 different healthcare facilities of four counties in the United States [26]. In brief, the earlier the index case is identified, isolated and cohorted, and contact patients are identified and screened, the lower is the risk of additional crosstransmissions [15].

Our study has potential limitations since it was not a randomised, controlled trial aiming at assessing direct causality between intervention and outcome. The occurrence of the first outbreaks in our institution and the rapid spread of CPE in neighbouring countries $[4,15,27]$ triggered quick and strong actions to control this emerging problem, contraindicating randomised comparative studies. However, the fact that the strength and the nature of the enhanced measures implemented after 2009 markedly differed from those applied before 2009, as well as the length of the continuous and systematic surveillance of every CPE event, justify to consider this study as quasi-experimental with pre-test and post-test periods [28].

We checked that the differences in number of secondary cases observed between the types of measures were not due to bias in species, enzyme and type of ward where the index case was admitted. Indeed, the distribution of the two main species ( $K$. pneumoniae versus $E$. coli), the two main enzymes (KPC versus OXA-48) and the three main types of wards (medicine, surgery or intensive care unit) did not differ for each category of measures (data not shown).

In conclusion, this study shows that, although the number of CPE index cases increased in our region due to admission and increased screening of carriers having been recently hospitalised or stayed abroad (Figure 1) [5], and although some secondary cases occurred, particularly when the implementation of control measures was delayed, the number of outbreaks and of secondary cases can be strongly limited by a specific control programme. Such a programme requires quick and sustained involvement of all stakeholders, particularly the infection control teams, medical and nursing staff, microbiologists and hospital administrators [15]. The strong commitment of the AP-HP institution, continuous coordination and support by the CICT, as well as a continuous feedback stimulated the efforts made in each hospital. Early detection of emerging drug resistant bacteria such as CPE and an active control programme must be developed and implemented at a national level to avoid CPE spread $[15,29]$. Institutional programmes, based on a coordinated policy, such as the one presented here, are efficient ways to bring together and motivate hospital staff and managers, and to promote quality and safety in healthcare.

\section{Members of the AP-HP Outbreaks Control Group}

Antoine Andremont, Laurence Armand-Lefevre, Gabriel Birgand, Christine Bonnal, Jean-Christophe Lucet, Hôpital Bichat, AP-HP, Paris, France; Guillaume Arlet, Michel Denis, Hôpital Tenon, AP-HP, Paris, France; Marie- Thérèse Baixench, Hervé Blanchard, Anne Casetta, Hélène Poupet, Hôpital Cochin, AP-HP, Paris, France; Frédéric Barbut, Dominique Decré, Jean-Claude Petit, Hôpital Saint Antoine, AP-HP, Paris, France; Patrick Berche, Jean-Ralph Zahar, Hôpital Necker, AP-HP, Paris, France; Edouard Bingen, Catherine Doit, Hôpital Robert Debré, AP-HP, Paris, France; Emmanuelle Cambau, Jean-Michel Guérin, Laurent Raskine, Hôpital Lariboisière, AP-HP, Paris, France; Anne Carbonne, Guillaume Kac, Isabelle Podglajen, Hôpital Européen Georges Pompidou, AP-HP, Paris, France; Jean-Winoc Decousser, Véronique Derouin, Florence Doucet-Populaire, Hôpital Antoine Béclère, AP-HP, Clamart, France; Laurence Drieux-Rouzet, Hôpital Charles Foix, AP-HP, Ivry Sur Seine, France; Florence Espinasse, Beate Heym, Hôpital Ambroise Paré, AP-HP, Boulogne, France; Nicolas Fortineau, Patrice Nordmann, Hôpital Bicêtre, AP-HP, Kremlin-Bicêtre, France; Jean-Louis Herrmann, Christine Lawrence, Hôpital Raymond Poincaré, AP-HP, Garches, France; Chloé Jansen, Patrick Legrand, Philippe Lesprit, Hôpital Henri Mondor, AP-HP, Créteil, France; Monique Duviquet, Hôpital Vaugirard, AP-HP, Paris, France; Anani Akpabie, Hôpital Emile Roux, 
Limeil-Brévannes, France; Najiby Kassis-Chikhani, Hôpital Paul Brousse, AP-HP, Villejuif, France; Géraldine Marcadé, Vincent Fihman, Hôpital Louis Mourier, AP-HP, Colombes, France; Simone Nerome, Marie-Hélène Nicolas-Chanoine, Hôpital Beaujon, AP-HP, Clichy, France; Bertrand Picard, Delphine Seytre, Hôpital Avicenne, AP-HP, Bobigny, France; Jérôme Robert, Hôpital Pitié-Salpêtrière, AP-HP, Paris, France; Jean-Louis Pons, Martine Rouveau, Hôpital Saint Louis, AP-HP, Paris, France; Nadine Sabourin, Hôpital JoffreDupuytren, AP-HP, Draveil, France; Isabelle Simon, Hôpital Sainte Périne, AP-HP, Paris, France.

\section{Acknowledgments}

We thank Michèle Nion-Huang, Jean-Yves Fagon and Michel Fournier from the central administration for their commitment in implementation of the CPE control programme.

\section{Conflict of interest}

None declared.

\section{Authors' contributions}

Sandra Fournier participated in the design of the programme, performed the survey, analysed the data, and wrote the manuscript. Catherine Monteil performed statistical analysis. Margaux Lepainteur participated in the survey. Christian Brun-Buisson participated in the design of the programme and revised the manuscript. Christian Richard, from AP-HP Central administration, sustained the implementation of the programme. Vincent Jarlier participated in the design of the programme, in the data analysis and revised the manuscript. Members of the AP-HP Outbreaks Control Group implemented the CPE control programme in AP-HP hospitals and organised the laboratory-based survey and CPE

\section{References}

1. Carmeli Y, Akova M, Cornaglia G, Daikos GL, Garau J, Harbarth $S$, et al. Controlling the spread of carbapenemase-producing Gram-negatives: therapeutic approach and infection control. Clin Microbiol Infect. 2010;16(2):102-11. http://dx.doi. org/10.1111/j.1469-0691.2009.03115.x

2. Cantón R, Akóva M, Carmeli Y, Giske CG, Glupczynski Y, Gniadkowski M, et al. Rapid evolution and spread of carbapenemases among Enterobacteriaceae in Europe. Clin Microbiol Infect. 2012;18(5):413-31. http://dx.doi. org/10.1111/j.1469-0691.2012.03821.x

3. Kumarasamy KK, Toleman MA, Walsh TR, Bagaria J, Butt $F$, Balakrishnan R, et al. Emergence of a new antibiotic resistance mechanism in India, Pakistan, and the UK: a molecular, biological, and epidemiological study. Lancet Infect Dis. 2010;10(9):597-602. http://dx.doi.org/10.1016/ S1473-3099(10)70143-2

4. European Centre for Disease Prevention and Control (ECDC). Antimicrobial resistance surveillance in Europe 2011. Annual Report of the European Antimicrobial Resistance Surveillance Network (EARS-Net). Stockholm: ECDC; 2012. Available from: http://www.ecdc.europa.eu/en/publications/publications/ antimicrobial-resistance-surveillance-europe-2011.pdf

5. Vaux S, Carbonne A, Thiolet JM, Jarlier V, Coignard B; RAISIN and Expert Laboratories Groups. Emergence of carbapenemase-producing Enterobacteriaceae in France, 2004 to 2011. Euro Surveill. 2011;16(22).

6. Kassis-Chikhani N, Saliba F, Carbonne A, Neuville S, Decre D, Sengelin C, et al. Extended measures for controlling an outbreak of VIM-1 producing imipenem-resistant Klebsiella pneumoniae in a liver transplant centre in France, 2003-2004. Euro Surveill. 2010;15(46). pii: 19713.

7. Jarlier V, Trystram D, Brun-Buisson C, Fournier S, Carbonne A, Marty L, et al. Curbing methicillin-resistant Staphylococcus aureus in 38 French hospitals through a 15-year institutional control program. Arch Intern Med. 2010;170(6):552-9. http:// dx.doi.org/10.1001/archinternmed.2010.32
8. Société Française de Microbiologie (SFM). Comité de l'Antibiogramme de la Société Française de Microbiologie. [Antibiogram committee of the French Society for Microbiology]. Paris: SFM; 2013. French. Available from: http://www.resapath.anses.fr/resapath_uploadfiles/files/ Documents/2013_CASFM.pdf

9. Nordmann P, Gniadkowski M, Giske CG, Poirel L, Woodford $\mathrm{N}$, Miriagou V, et al. Identification and screening of carbapenemase-producing Enterobacteriaceae. Clin Microbiol Infect. 2012;18(5):432-8. http://dx.doi. org/10.1111/j.1469-0691.2012.03815.x

10. Fournier S, Lepainteur M, Kassis-Chikhani N, Huang M, BrunBuisson C, Jarlier V. Link Between Carbapenemase-Producing Enterobacteria Carriage and Cross-Border Exchanges: Eight-Year Surveillance in a Large French Multihospitals Institution. J Travel Med. 2012;19(5):320-3. http://dx.doi. org/10.1111/j.1708-8305.2012.00641.X

11. Carbonne A, Thiolet JM, Fournier S, Fortineau N, KassisChikhani N, Boytchev I, et al. Control of a multi-hospital outbreak of KPC-producing Klebsiella pneumoniae type 2 in France, September to October 2009. Euro Surveill. 2010;15(48). pii: 19734 .

12. Decre D, Birgand G, Geneste D, Maury E, Petit JC, Barbut F, et al. Possible importation and subsequent cross-transmission of OXA-48-producing Klebsiella pneumoniae, France, 2010. Euro Surveill. 2010;15(46). pii: 19718.

13. Institut de veille sanitaire (InVS). Episodes impliquant des entérobactéries productrices de carbapénèmases en France. Situation épidémiologique du 3 octobre 2012. Paris: InVS. French. Available from: http://www.invs.sante.fr/Dossiersthematiques/Maladies-infectieuses/Infections-associees-auxsoins/Surveillance-des-infections-associees-aux-soins-IAS/ Enterobacteries-productrices-de-carbapenemases-EPC/ Episodes-impliquant-des-enterobacteries-productrices-decarbapenemases-en-France.-Situation-epidemiologique-du-3octobre-2012.

14. Grundmann H, Livermore DM, Giske CG, Canton R, Rossolini GM, Campos J, et al. Carbapenem-non-susceptible Enterobacteriaceae in Europe: conclusions from a meeting of national experts. Euro Surveill. 2010;15(46). pii: 19711.

15. Schwaber MJ, Lev B, Israeli A, Solter E, Smollan G, Rubinovitch B, et al. Containment of a country-wide outbreak of carbapenem-resistant Klebsiella pneumoniae in Israeli hospitals via a nationally implemented intervention. Clin Infect Dis. 2011;52(7):848-55. http://dx.doi.org/10.1093/cid/ciro25

16. Cohen MJ, Block C, Levin PD, Schwartz C, Gross I, Weiss Y, et al. Institutional control measures to curtail the epidemic spread of carbapenem-resistant Klebsiella pneumoniae: a 4-year perspective. Infect Control Hosp Epidemiol. 2011;32(7):673-8. http://dx.doi.org/10.1086/660358

17. Borer A, Eskira S, Nativ R, Saidel-Odes L, Riesenberg K, Livshiz-Riven I, et al. A multifaceted intervention strategy for eradication of a hospital-wide outbreak caused by carbapenem-resistant Klebsiella pneumoniae in Southern Israel. Infect Control Hosp Epidemiol. 2011;32(12):1158-65. http://dx.doi.org/10.1086/662620

18. Agodi A, Voulgari E, Barchitta M, Politi L, Koumaki V, Spanakis N, et al. Containment of an Outbreak of KPC-3producing Klebsiella pneumoniae in Italy. J Clin Microbiol. 2011;49(11):3986-9. http://dx.doi.org/10.1128/JCM.01242-11

19. Kochar S, Sheard T, Sharma R, Hui A, Tolentino E, Allen G, et al. Success of an infection control program to reduce the spread of carbapenem-resistant Klebsiella pneumoniae. Infect Control Hosp Epidemiol. 2009;30(5):447-52. http://dx.doi. org/10.1086/596734

20. Fournier S, Brossier F, Fortineau N, Gillaizeau F, Akpabie A, Aubry A, et al. Long-term control of vancomycin-resistant Enterococcus faecium at the scale of a large multihospital institution: a seven-year experience. Euro Surveill. 2012;17(30). pii: 20229.

21. Struelens MJ, Monnet DL, Magiorakos AP, Santos O'Connor F, Giesecke J. New Delhi metallo-beta-lactamase 1-producing Enterobacteriaceae: emergence and response in Europe. Euro Surveill. 2010;15(46). pii: 19716.

22. Lepelletier D, Andremont A, Grandbastien B. Risk of highly resistant bacteria importation from repatriates and travelers hospitalized in foreign countries: about the French recommendations to limit their spread. J Travel Med. 2011;18(5):344-51. http://dx.doi. org/10.1111/j.1708-8305.2011.00547.x

23. Akova M, Daikos GL, Tzouvelekis L, Carmeli Y. Interventional strategies and current clinical experience with carbapenemase-producing Gram-negative bacteria. Clin Microbiol Infect. 2012;18(5):439-48. http://dx.doi. org/10.1111/j.1469-0691.2012.03823.x 
24. O'Brien DJ, Wrenn C, Roche C, Rose L, Fenelon C, Flynn A, et al. First isolation and outbreak of OXA-48-producing Klebsiella pneumoniae in an Irish hospital, March to June 2011. Euro Surveill. 2011;16(29). pii: 19921.

25. Steinmann J, Kaase M, Gatermann S, Popp W, Steinmann E, Damman M, et al. Outbreak due to a Klebsiella pneumoniae strain harbouring KPC-2 and VIM-1 in a German university hospital, July 2010 to January 2011. Euro Surveill. 2011;16(33). pii: 19944 .

26. Won SY, Munoz-Price LS, Lolans K, Hota B, Weinstein RA, Hayden MK. Emergence and rapid regional spread of Klebsiella pneumoniae carbapenemase-producing Enterobacteriaceae. Clin Infect Dis. 2011;53(6):532-40. http://dx.doi.org/10.1093/ $\mathrm{cid} / \mathrm{cir} 482$

27. Vatopoulos A. High rates of metallo-beta-lactamase-producing Klebsiella pneumoniae in Greece--a review of the current evidence. Euro Surveill. 2008;13(4). pii: 8023.

28. Harris AD, Bradham DD, Baumgarten M, Zuckerman IH, Fink JC, Perencevich EN. The use and interpretation of quasiexperimental studies in infectious diseases. Clin Infect Dis. 2004;38(11):1586-91. http://dx.doi.org/10.1086/420936

29. Schwaber MJ, Carmeli Y. Carbapenem-resistant Enterobacteriaceae: a potential threat. JAMA. 2008;300(24):2911-3. http://dx.doi.org/10.1001/ jama.2008.896 